\title{
Analysis of a Prefabricated Vertical Drain (PVD) Soil Improvement Project
}

\author{
Ahmet Can MERT ${ }^{1}$ \\ Akın ÖNALP2 \\ Ersin AREL ${ }^{3}$
}

\begin{abstract}
A settlement analysis has been carried out for several sectors of a rail station yard improved with prefabricated vertical drains (PVD) in Istanbul, that exhibited prolonged consolidation beyond the predicted values in certain sectors of the treated zone. Final settlement and End of Primary (EOP) settlement times have been estimated theoretically as well as using the Asaoka graphical procedure. The compliance of settlement-time curves with in-situ measurements and Asaoka solution has been investigated. A geotechnical model was developed for finite element and three-dimensional consolidation analyses. The settlement curves obtained by varying horizontal-vertical permeability coefficient ratio $\left(k_{h} / k_{v}\right)$ and insitu measurements have been compared, and $k_{h} / k_{v}$ values corresponding to $90 \%$ degree of consolidation has been computed for all sectors. The effect of drain spacing $\left(s_{\text {drain }}\right)$ as well as drain length $\left(L_{\text {drain }}\right)$ on the rate of consolidation have been evaluated for each sector, keeping the specified ratios constant. The times corresponding to $95 \%$ degree of consolidation $\left(t_{95}\right)$ have been calculated using the theoretical solution and compared to in-situ measurements. Calculated $t_{95}$ 's has also been compared to their estimated values by varying the spacing $\left(s_{\text {drain }}\right)$ and the length $\left(L_{\text {drain }}\right)$. Additionally, the required intervals of $s_{\text {drain }}$ and $L_{\text {drain }}$ have been obtained corresponding to the calculated $t_{95}$ times. The analyses suggest that the main reason for prolonged consolidation was the horizontal to vertical permeability coefficient ratio. According to the analysis results, PVD implementation was not efficient in clays having $k_{h} / k_{v}$ of approximately unity. The main conclusion of this study was to discover the necessity for optimizing the variables in any such project. The efficacy of the works can be significantly enhanced if simultaneous evaluation of the parameters $s_{\text {drain }}$ and $L_{\text {drain }}$ and the permeability
\end{abstract}

Note:

- This paper was received on November 1, 2019 and accepted for publication by the Editorial Board on August 17, 2020.

- Discussions on this paper will be accepted by March 31, 2022.

- https://doi.org/10.18400/tekderg.641218

1 Istanbul Kultur University, Department of Civil Engineering, Istanbul, Turkey - a.mert@iku.edu.tr https://orcid.org/0000-0002-2483-1330

2 Istanbul Okan University, Department of Civil Engineering, Istanbul, Turkey - akin.onalp@okan.edu.tr https://orcid.org/0000-0003-1906-0153

3 Istanbul Okan University, Department of Civil Engineering, Istanbul, Turkey, ersin.arel@okan.edu.tr https://orcid.org/0000-0001-9424-2198 
ratio $k_{h} / k_{v}$ is carried out prior to field work. Otherwise, "accidents" may emerge as found out in this project.

Keywords: Prefabricated Vertical Drain (PVD), radial consolidation, 3D consolidation, acceleration of consolidation, consolidation settlement, coefficient of permeability, degree of consolidation, consolidation rate, asaoka procedure, numerical analysis.

\section{INTRODUCTION}

Consolidation of soils has been one of the frequently investigated topics, perhaps because full success in estimating the rate of settlement still avoids the geotechnician. The process of consolidation may be long in clays, since there is a considerable time lag between the application of load and full dissipation of the excess pore water pressures generated.

Improvement may be necessary for clays which require a time longer than the acceptable for the completion of the primary consolidation (EOP) before construction activity starts. One of the commonly used methods for shortening the process is the use of sand drains, or more recently, prefabricated vertical drains (PVD) which provide horizontal drainage in addition to vertical, to dissipate excess pore pressures rapidly. PVD accelerates the process in accordance with the radial consolidation theory. The most influential soil property thus becomes the horizontal coefficient of permeability $\left(k_{h}\right)$. Other essential parameters are drain horizontal spacing $(s)$ and drain installation length $(L)$. Drain spacing should be optimized in order that an efficient remediation is secured. In connection with the installation length, drains should fully penetrate the layer to be consolidated, to secure efficient horizontal drainage. Contrary to Terzaghi one dimensional consolidation theory [1], radial consolidation considers the movement of water through a soil both vertically and laterally. Indeed, Terzaghi emphasized that his assumptions made in the 1D theory should be used with caution by considering the real behavior of soil [2]. The earliest study regarding three-dimensional consolidation has been made by using the elasticity theory with the assumption that water flows through vertical and random planes in a clay medium [3]. It has been discovered through field practice over the years that application of vacuum to the system may be necessary to enhance the efficiency of the system where the ratio $\left(k_{h} / k_{v}\right)$ is not found to be sufficiently high.

The total degree of consolidation for an undisturbed and PVD-improved soil layer is expressed by both radial $\left(U_{r}\right)$ and vertical $\left(U_{z}\right)$ degrees of consolidation [4]:

$$
\left(1-U_{z r}\right)=\left(1-U_{r}\right)\left(1-U_{z}\right)
$$

Extensive research has been carried out to estimate the radial degree of consolidation $U_{r}$ [5, $6,7]$. One of the commonly used expressions was proposed by Rendulic [5]. In his study, it was shown that $U_{r}$ is a function of the coefficient of radial consolidation $\left(c_{v r}\right)$ and radial time factor $\left(T_{r}\right)$. Radial degree of consolidation for equal strain condition may be written by using the PVD parameters [6]:

$$
U_{r}=1-\exp \left(\frac{-8 T_{r}}{\alpha}\right)
$$


The coefficient $\alpha$ in Equation (2) depends on drain spacing $s$. Although the equations developed have been primarily intended for sand drains, they are also applicable for PVD use. The difference emerges in coefficient $\alpha$, since wick drains are not cyclindrical. Barron's solution for $U_{r}$ can be rearranged considering equivalent effective PVD diameter $D$, and the end of consolidation time $t$ for PVD-improved soil is written as [8]:

$t=\frac{D^{2}}{8 c_{v r}}\left[\ln \frac{D}{d}-\frac{3}{4}\right] \ln \frac{1}{1-U_{r}}$

where $D$ can be taken as $1.05 \mathrm{~s}$ for triangular pattern and $1.128 \mathrm{~s}$ for rectangular grid applications. Equivalent drain diameter $d$ can be taken as half of the drain width $d=b / 2$. The main parameter for radial consolidation is the coefficient of consolidation $\left(c_{h} \equiv c_{v r}\right)$ or permeability $\left(k_{h}\right)$ in lateral direction. Vertical and horizontal permeability of soils, hence the corresponding coefficients of consolidation $\left(c_{v}, c_{h}\right)$, may differ considerably and it has been determined that horizontal to vertical permeability ratio $k_{h} / k_{v}$ may vary from 2 to 10 [9].

A recent study presented a $2 \mathrm{D}$ and $3 \mathrm{D}$ numerical simulation of vacuum assited PVD application and the results were compared with two previously investigated studies (Suvarnabhumi Airport, Thailand and Tianjin Port, China). A design chart for drain spacing was provided based on the results obtained from the two case histories [10]. Another recently published research emphasized the influence of soil permeability on the use of PVD application with vacuum preloading [11]. The research revealed that the change in permeability especially for large strain can affect the flow characteristics through the soil and vertical drain. Large-strain case was also investigated by another group for vertical drain with preloading where the use of non-linear solutions was emphasized [12].

In the present study, consolidation analyses were carried out for the sectors of a PVDimproved project in Halkali region of Istanbul, which exhibited prolonged consolidation beyond the predicted EOP values, contrary to the case histories presented in the literature $[13,14,15]$.

Different horizontal to vertical permeability coefficient ratios $\left(k_{h} / k_{v}\right)$ were specified for calculations in all sectors of ongoing consolidation to understand the process. In addition to varying the ratios, effect of drain spacing as well as that of drain length on the rate of consolidation time were investigated using conventional 3D consolidation approach, numerical analysis and the empirical Asaoka procedure.

\section{FEATURES OF THE REMEDIATION AREA}

Normally consolidated (NL) lacustrine clays have been improved by PVD application accompanied by preloading at a rail station yard, which is known to have exhibited excessive settlements under traffic and the ancillary structures, throughout the last century. Although the tracks can tolerate settlements of up to $50 \mathrm{~mm}$, the critical issue at the new station was the limiting differential settlements of the passenger platforms and the tracks, which should not exceed $25 \mathrm{~mm}$. 
To mitigate this by PVD application, the designer calculated that a period of up to 180 days would be sufficient to achieve the foreseen settlements and subsequently complete the construction of the station platforms and the tracks leading to them. This would have enabled the contractor to prevent future settlements and meet the deadlines. This paper gives an account of the events and calculations that led to the failure of meeting the date foreseen for EOP's.

\subsection{Soil Profile and Soil Properties at the Improvement Site}

The investigated site contains young alluvial and lacustrine deposits overlying limestonemarl bedrock. The segment of this layer above the ground water level (GWL) at 1.5-2.0 m. is lightly over-consolidated by desiccation. Another identified layer is a dark-gray, greenishgray and green Quaternary (Holocene) aged normally consolidated (NL) clay of Kusdili Formation which extends under the alluvial layer at varying thicknesses of up to $35 \mathrm{~m}$. The borehole locations for the studied sectors Sector 1A, 1B and 5B are shown in Figure 1. Figure 2 depicts two characteristic soil profiles from the site.

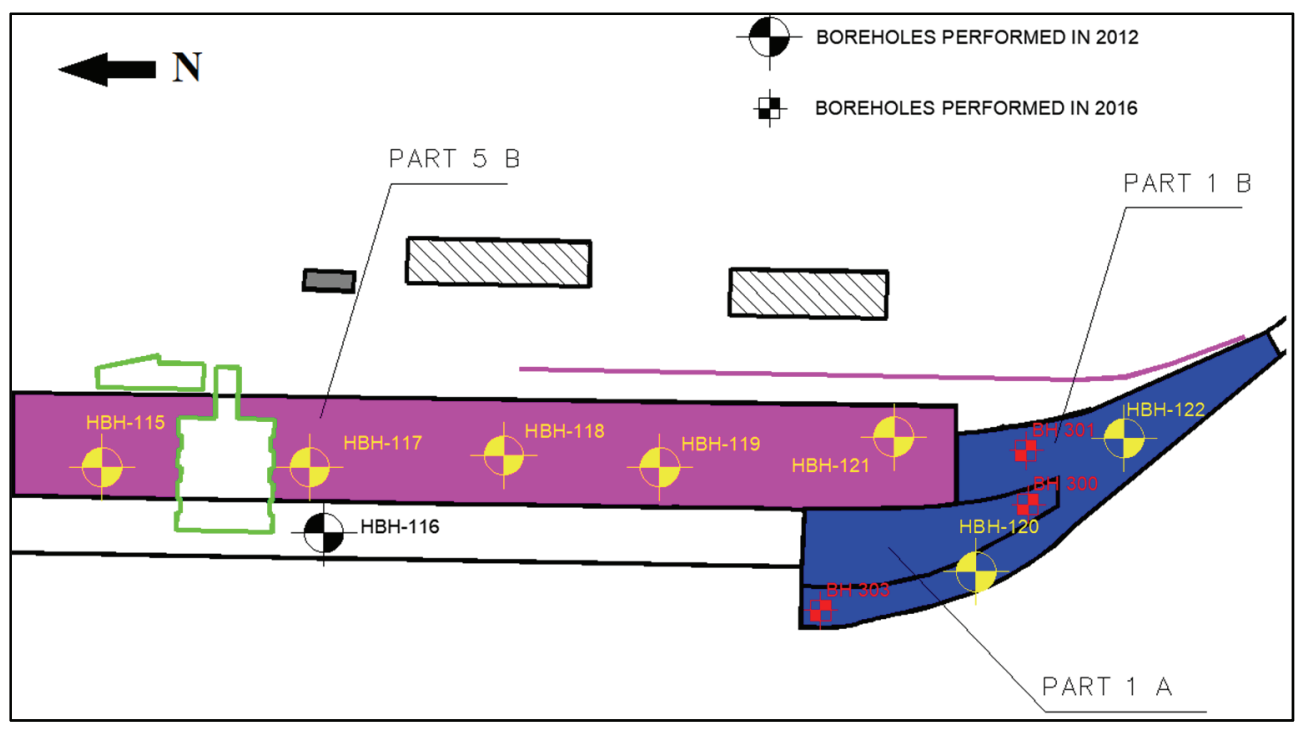

Figure 1 - Borehole locations of Sectors $1 A, 1 B$ and 5B (Scale 1:5000)

Samples from the boreholes drilled in 2012 and 2016 were classified by the Unified Soil Classification System USCS [16]. According to the test results, alluvial samples from 3-6m depths classify as ML, CL and SW-SM and Kusdili NL clays under the alluvium classified as $\mathrm{CL}$ and $\mathrm{CH}$. The layers have natural moisture contents $\left(w_{n}\right)$ mostly at around the liquid limit $\left(w_{L}\right)$ or slightly below (Figure $\left.3 a\right)$. Liquidity indices $\left(I_{L}\right)$ are typically $0.55-0.93$ rising to unity with increasing depth (Figure 3b). Quick triaxial tests (UU) performed on Kusdili clays indicated undrained shearing resistances $\left(S_{u}\right)$ as low as 10-21 kPa (Figure 3c). 


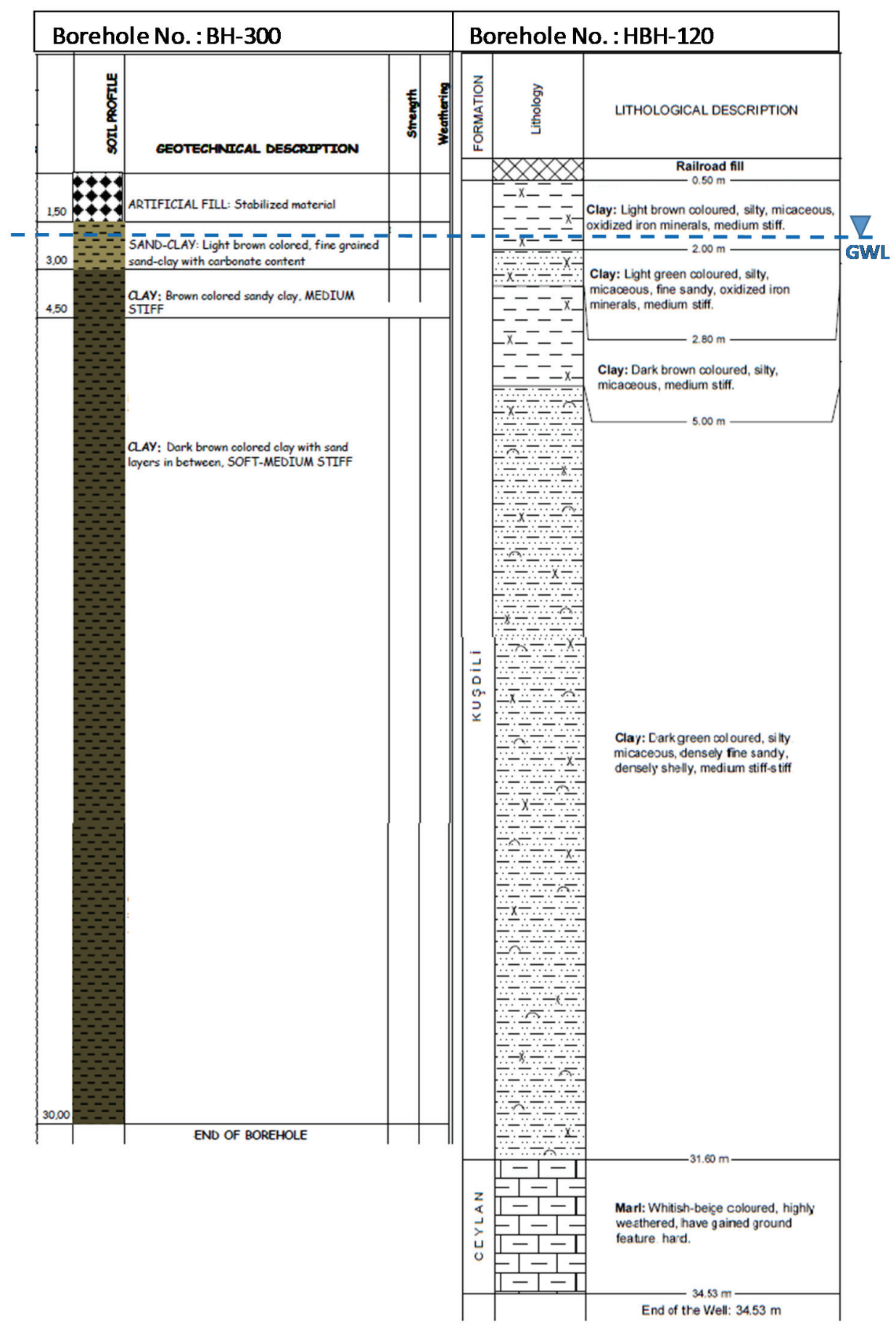

Figure 2 - Representative soil profiles from the boreholes at the study area 

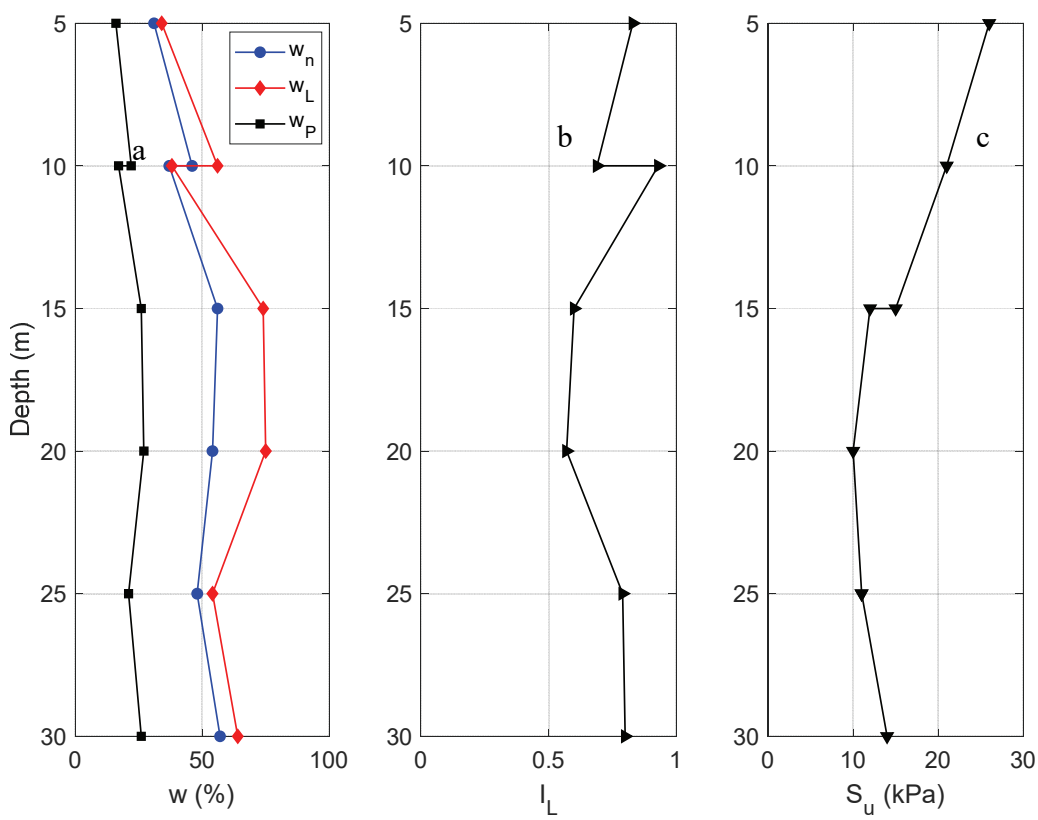

Figure 3 - Depth (z) versus a) consistency limits, b) liquidity index and c) undrained strength

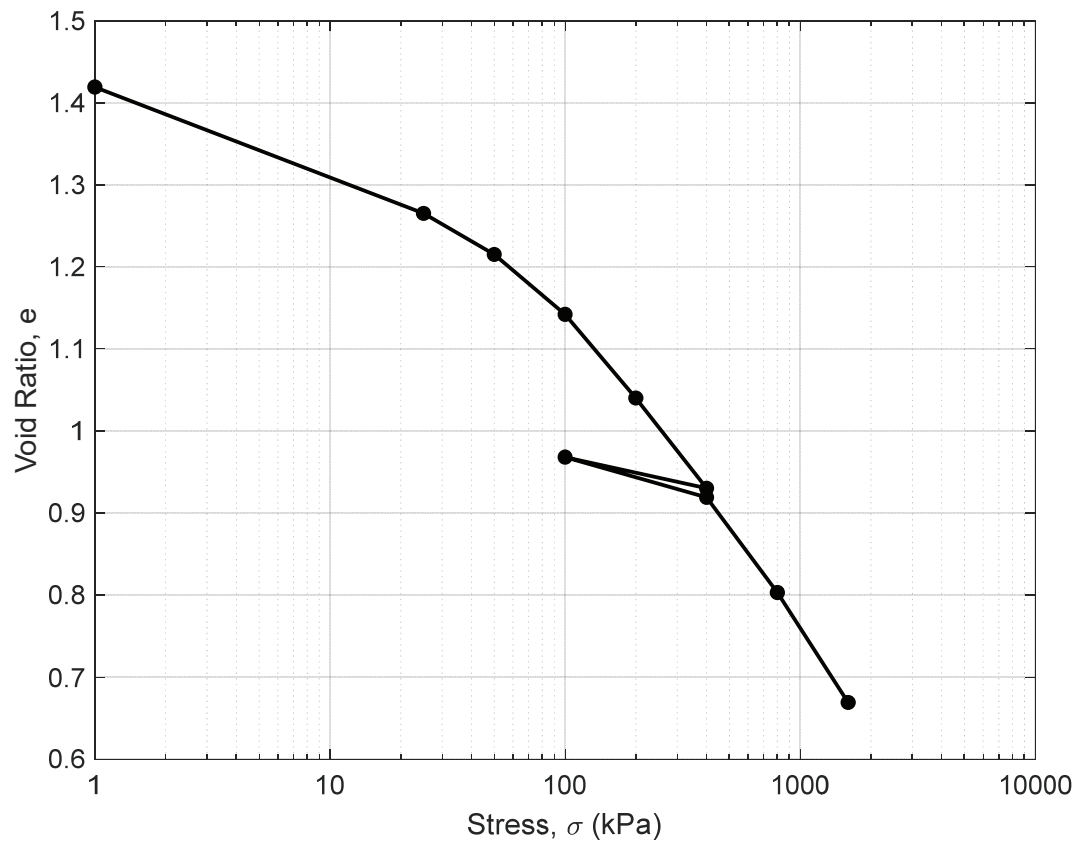

Figure 4 - Characteristic oedometer test result for NL Kusdili Clay 
The laboratory test results confirmed that the Kusdili layer consists of soft normally consolidated and lightly overconsolidated clays (Figure 4) with poorly defined boundaries.

In addition to classification and triaxial testing (TX-UU), oedometer tests have been performed to carry out consolidation analyses for the clays to be improved. Oedometer test results illustrated in Figure 5 show that Kusdili clay layer has overconsolidation ratios of $\mathrm{OCR}=1 \sim 1.5$, and the clay has a vertical permeability of $k_{v}=10^{-6} \mathrm{~m} /$ day. The compression index for the layer was found to rise as high as $C_{c}=0.673$.
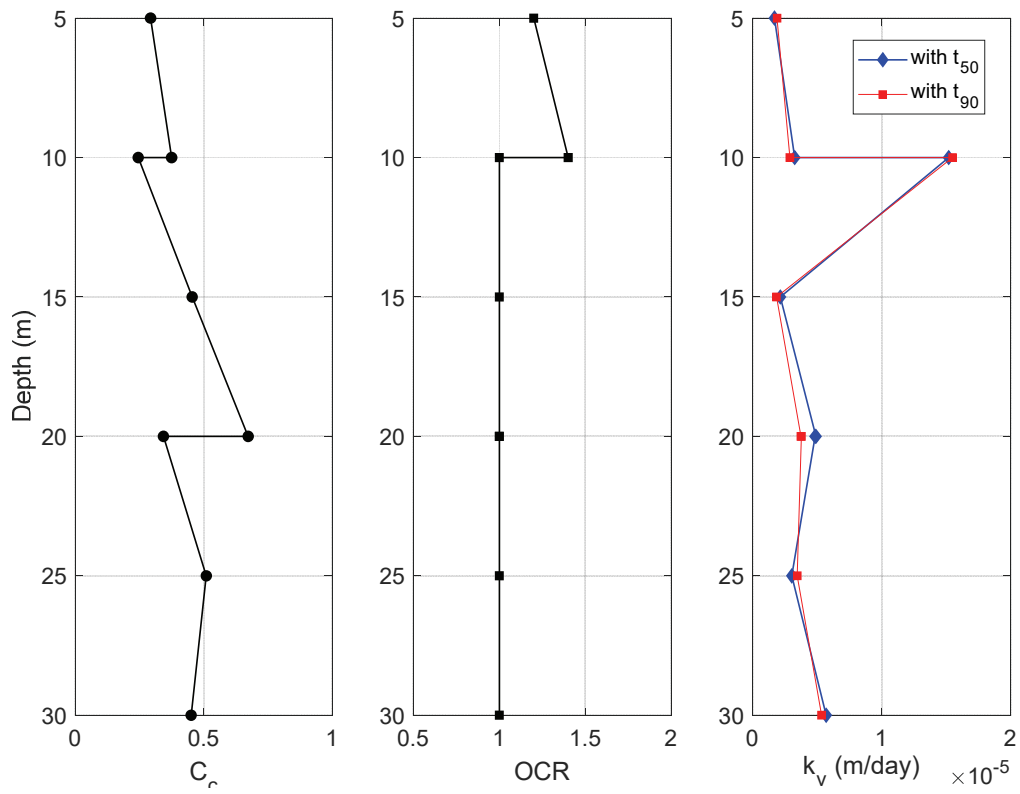

Figure 5 - Oedometer test results by depth

\subsection{Implemented PVD Patterns}

The designer had selected preloading with PVD as the improvement method to reach the excessive consolidation settlements anticipated at the project site. This was proved to be a feasible solution to achieve the final settlements at the preloaded sectors Sector 3A, 4; and PVD-improved sectors 2A, 2C, 3B, 5A, 5C rapidly. However, the settlements recorded at Sectors $1 \mathrm{~A}, 1 \mathrm{~B}$ and $5 \mathrm{~B}$ after treatment not only exceeded the predicted values, but they continued to increase well beyond the estimated EOP times. Table 1 lists the stated details of treatment applied by the contractor at those "problem" sectors.

Figure 6 illustrates settlement-time $(\Delta-\mathrm{t})$ curves for the sectors monitored. These curves were plotted using the data from among the settlement plate readings at which the highest values for that specific sector was recorded. The time estimated for EOP by the designer was 6 to 10 months following the PVD application. However, the curves indicated ongoing settlement well beyond 1000 days. Measurements indicated that settlements reached $600-800 \mathrm{~mm}$, up to $45 \%$ above the predicted values, in 1201 to 1906 days elapsed. More significantly, the durations for EOP were extended unacceptably, obliging the owner of the facility to resort to 
the use of piling down to the bedrock about $25-35 \mathrm{~m}$ below, to catch up with the deadline. Table 2 summarises this paradoxical situation.

Table 1 - PVD Protocol

\begin{tabular}{|c|c|c|c|c|}
\hline SECTOR & $\begin{array}{c}\text { SPACING, } \mathrm{s}_{\text {drain }} \\
(\mathrm{m})\end{array}$ & $\begin{array}{c}\text { LENGTH, } \mathrm{L}_{\text {drain }} \\
(\mathrm{m})\end{array}$ & PRELOAD & AREA $\left(\mathrm{m}^{2}\right)$ \\
\hline 1A & $1 \mathrm{x} 1$ & 20 & $3.0 \mathrm{~m}$ & 5134 \\
\hline 1B & $2 \times 2$ & 26 & $2.5 \mathrm{~m}$ & 10629 \\
\hline 5B & $2 \mathrm{x} 2$ & 24 & $2.0 \mathrm{~m}$ & 16307 \\
\hline
\end{tabular}

Table 2 - Estimated settlements and in situ measurement results

\begin{tabular}{|c|l|c|c|c|c|}
\hline SECTOR & $\begin{array}{l}\text { Designer } \\
\text { Predicted } \\
\text { Settlement }(\mathrm{mm})\end{array}$ & $\begin{array}{c}\text { InSitu Final } \\
\text { Measurement } \\
(\mathrm{mm})\end{array}$ & $\begin{array}{c}\text { Error in } \\
\text { estimation }\end{array}$ & $\begin{array}{c}\text { Estimated EOP } \\
\text { time (Days) }\end{array}$ & $\begin{array}{c}\text { Time } \\
\text { Elapsed } \\
\text { (Days) }\end{array}$ \\
\hline 1A & 650 & 793 & $22 \%$ & 180 & 1906 \\
\hline 1B & 450 & 627 & $39 \%$ & 180 & 1201 \\
\hline 5B & 410 & 597 & $46 \%$ & 180 & 1271 \\
\hline
\end{tabular}

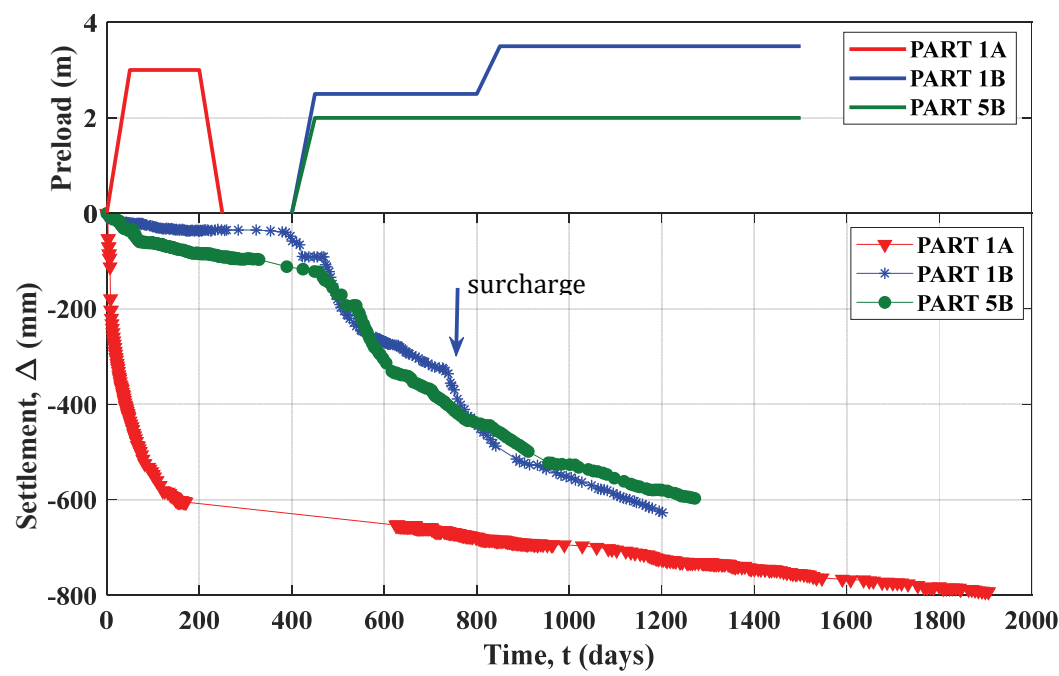

Figure 6 - Settlement-time (A-t) measurements for Sector $1 A, 1 B$ and $5 B$

The height of the embankment at Sector 1B was increased by $1 \mathrm{~m}$ at 738 days, in order to be able to interpret the development of the process. The settlements responded almost proportionally, showing the effects of the surcharge in the implemented area, along with the neighbouring sectors (Figure 6). 


\section{EVALUATION OF SETTLEMENT AND PVD DESIGN}

\subsection{Analysis for Estimated and Measured Settlements}

Evaluation of PVD performance requires regular in-situ monitoring. The objective of PVD application is to reach the completion of consolidation settlement (EOP) within the estimated time. Site measurements are made as either settlements or porewater pressures. The study by Hansbo et al. on vertical drains revealed that shearing resistance of the improved layer increased at constant porewater pressure, and they recommended the use of settlement measurements to evaluate the rate of consolidation [17]. Accordingly, frequent settlement measurements were carried out to evaluate the effect of PVD application on consolidation, intended for use to apply the Asaoka graphical procedure [18].

Asaoka diagram is constructed by plotting $n$ number of settlement measurements $\left(s_{n}\right)$ taken at equal time intervals $(\Delta t)$ against the previous value $\left(s_{n-l}\right)$ for each reading. He showed that the plotted points fit a straight line with the intercept $\beta_{0}$ and slope $\beta_{l}$ as given in Eq.6, and the intersection of this line with $y=x$ line is assumed to indicate the final settlement $\left(s_{f}\right)$ :

$$
s_{n}=\beta_{0}+\beta_{1} s_{n-1}
$$

From the slope $\beta_{l}$ and $c_{v}$ from oedometer results, the coefficient of radial consolidation $c_{h}$ can be calculated by,

$$
-\frac{\ln \beta_{1}}{\Delta t}=\frac{8 c_{h}}{D^{2} \alpha}+\frac{\pi^{2} c_{v}}{4 H^{2}}
$$

where $D$ and $\alpha$ are the terms defined in Eqs. 2 and3. $H$ is the drainage path length from onedimensional consolidation theory. $c_{h}$ is the controlling parameter and the term containing $c_{v}$ has less weight compared to the first term in the equation [19]. The expression for $j$-th settlement value $\left(s_{j}\right)$ and time corresponding to that value $t_{j}=\Delta t . j$ can be written as in Eq. 6 , provided that $s_{0}$ is the first settlement value employed. Equation (6) can also be used to calculate the time required to reach the final settlement $s_{f}$,

$$
s_{j}=\frac{\beta_{0}}{1-\beta_{1}}-\left(\frac{\beta_{0}}{1-\beta_{1}}-s_{0}\right)\left(\beta_{1}\right)^{j}
$$

Asaoka diagrams were plotted for Sectors 1A, 1B and 5B using the readings of the settlement plate that indicated the highest values in that sector. Figure 7 elucidates the measurements taken at the problematic sectors. The initial readings were omitted to avoid errors that may occur in the calculation. The final settlement $s_{f}$ for Sector $1 \mathrm{~A}$ was computed by using the measurements taken after placement of surcharge on the neighbouring sectors. The total final settlement for Sector $1 \mathrm{~A}$ is the sum of the last measurement taken before unloading and $s_{f}$ value obtained. The placement of surcharge at Sector 1B resulted in 'jumps' in the diagram. Final settlement for this sector was calculated using the measurements taken after surcharging. 

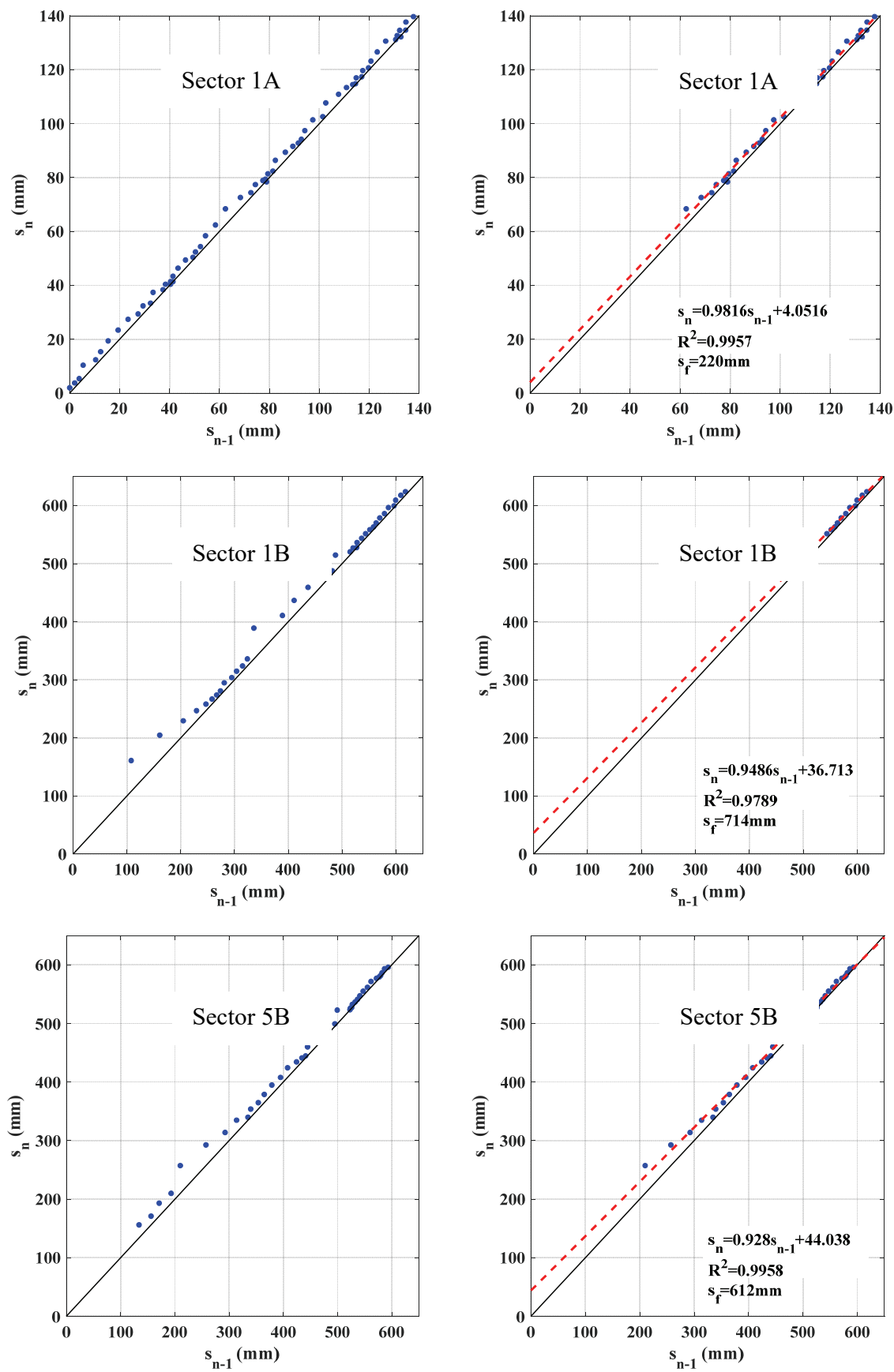

Figure 7 - Asaoka diagrams for Sector 1A, 1B, 5B 
The effect of $1 \mathrm{~m}$ surcharge applied at Sector $1 \mathrm{~B}$ has also been observed in Sector $5 \mathrm{~B}$ since this sector is in the settlement dish of Sector 1B. The final settlement for Sector $5 \mathrm{~B}$ was obtained using readings taken after surcharging, using the same procedure followed for Sector 1B (Figure 7). $\Delta$-t curves for each sector were plotted with the calculated final settlement and EOP by means of Eq. 8. These curves from Asaoka procedure were combined with the available in-situ measurements (Figure 8). In this way, the Asaoka solution and field measurements could be compared, and it was found that there is good agreement, providing a determination coefficient of $R^{2}>0.95$. In other words, the final settlements and EOP times from theoretical solution agreed with the in-situ measurements. Settlement readings showed increasing values when the preload was removed after 180 days at Sector 1A, and the measurements started to be taken after the surcharge took effect in Sector 1B, 454 days later. Figure 8 illustrates the combined $\Delta$-t curve for all the sections with Asaoka solution and insitu measurements following the removal of the preload. In situ data is in agreement with the theoretical solution. Preloading started at 397 and 467 days after the mesurements were initiated in Sector 1B and 5B, respectively. The effect of loading can be inferred from the site measurements (Figure 6). When the curves from Asaoka solution and in-situ measurements were combined for Sector $1 \mathrm{~B}$ and $5 \mathrm{~B}$, it was found that there is a strong tendency for the curves to coincide. The calculated final settlements were found to be significantly greater than the latest readings recorded in situ for all the sectors investigated. Additionally, the elapsed time for the last measurements were shorter than the computed EOP time from the Asaoka solution. This finding verified that consolidation settlement had not ceased at the sectors Sector 1A, 1B and 5B. Table 3 summarizes the results of evaluation of consolidation with Asaoka at the studied sectors.

Table 3 - Measured and estimated settlements and EOP

\begin{tabular}{|l|c|c|c|}
\hline & $\begin{array}{c}\text { SECTOR } \\
\text { 1A }\end{array}$ & $\begin{array}{c}\text { SECTOR } \\
\text { 1B }\end{array}$ & $\begin{array}{c}\text { SECTOR } \\
\text { 5B }\end{array}$ \\
\hline Final settlement measured (mm) & 793 & 627 & 597 \\
\hline Time (Days) & 1906 & 1201 & 1271 \\
\hline $\begin{array}{l}\text { Final Settlement estimated with Asaoka (mm) [Figure } \\
8]\end{array}$ & $873^{*}$ & 714 & 612 \\
\hline $\begin{array}{l}\text { Estimated Time to EOP from Asaoka Solution (Days) } \\
\text { [Eq.8] }\end{array}$ & 8376 & 3406 & 2396 \\
\hline $\begin{array}{l}\text { Coefficient of determination for the prediction [Figure } \\
\text { 7] }\end{array}$ & 0.996 & 0.979 & 0.996 \\
\hline
\end{tabular}

*Sum of sf by Asakoa $(220 \mathrm{~mm})$ and final reading before neighbouring preloads $(653 \mathrm{~mm})$

It has been determined that the three sectors of the site have exhibited prolonged consolidation, despite the use of PVD. Besides, the calculated final settlements were found to require extended periods well beyond the estimated durations foreseen at the design stage. 


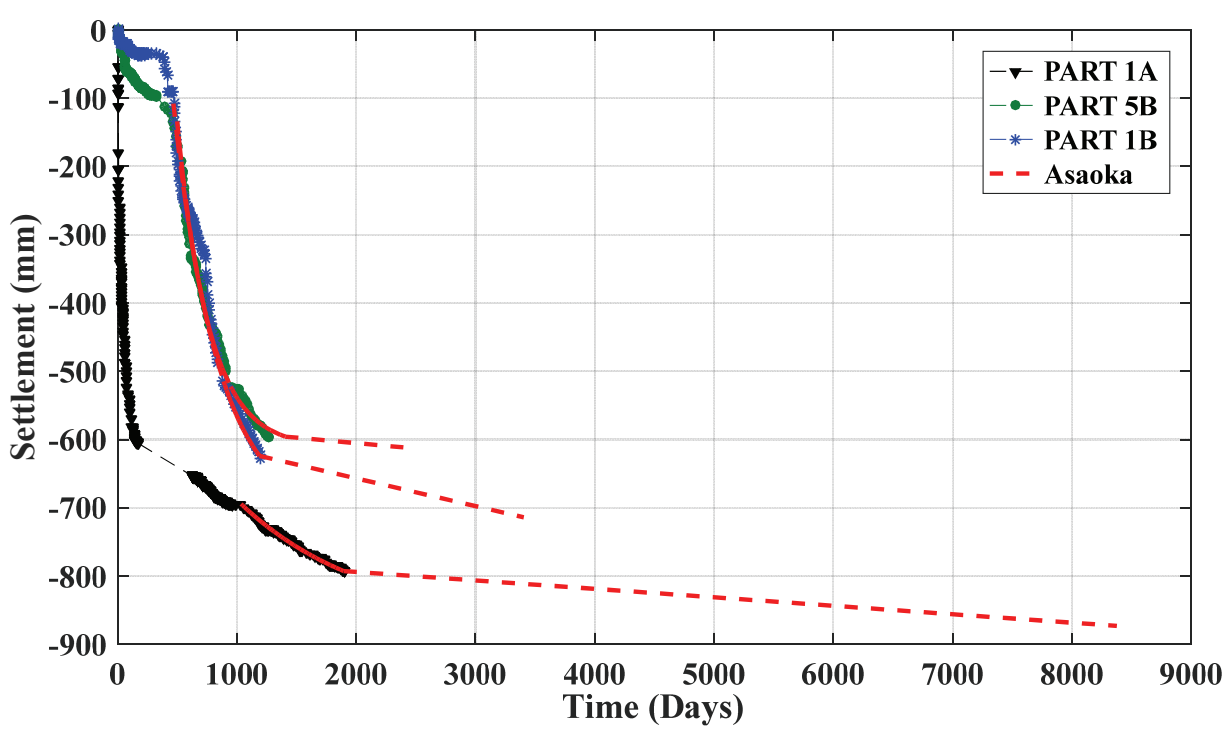

Figure 8 - 4-t curves extrapolated with Asaoka projection

\subsection{Numerical Analysis Models of PVD Design}

The effect of main PVD design parameters in the remediation area, namely the coefficients of consolidation $c_{h}$ or $k_{h}$, drain horizontal spacing $\left(s_{\text {drain }}\right)$, and drain length $\left(L_{d r a i n}\right)$, were investigated with three-dimensional consolidation analysis (abbreviated as 3DCONS) as well as the finite element method (FEM). Consolidation analyses were performed using the Settle3D software, and finite element code Plaxis2D. FEM models the soil with constitutive material equations for hardening and softening behaviour. PVDs were modelled as drain elements which consider zero excess porewater pressure along the drain in order that the pressure difference between drains and the surrounding soil provides simulation of radial drainage. 3DCONS models on the other hand, were solved with the conventional radial drainage equations whereby unlike FEM models, constitutive models are not required. The only soil parameter employed was the permeability coefficient, while other values such as the drain length and spacing were adopted from PVD design. The results from 3DCONS and FEM models for each sector were compared with Asaoka predictions and in-situ measurements. The soil profile and properties were assigned to the models from borehole information and laboratory test results. PVD's were modelled by employing the information in Table 1. The assigned soil layers and their properties for each sector are given in Table 4. The Ground Water Table was $1.5 \sim 2.0 \mathrm{~m}$ below the surface. The vertical coefficients of permeability employed in the models are listed in Table 5.

The final settlements calculated with the numerical models and Asaoka solution have been found to be higher than the latest in-situ measurements recorded, suggesting that consolidation was to continue in all the sectors investigated, had further monitoring been implemented. 
Table 4 - Assigned soil profile and properties used in 3DCONS and FEM models

\begin{tabular}{|c|c|c|c|c|c|c|}
\hline \multicolumn{7}{|c|}{ SECTOR 1A } \\
\hline & BALLAST & ALLUVIUM & KUSDILI CLAY & & & \\
\hline & $+3.00 \sim 0.00$ & $0.00 \sim-4.00$ & $>-4.00$ & & & \\
\hline Model & $\begin{array}{l}\text { Hardening } \\
\text { Soil }\end{array}$ & Soft Soil & Soft Soil & Unit & & \\
\hline$\rho_{\mathrm{n}}$ & 22 & 18 & 17 & $\mathrm{kN} / \mathrm{m}^{3}$ & & \\
\hline$\rho_{d}$ & 23 & 19 & 18 & $\mathbf{k N} / \mathbf{m}^{3}$ & & \\
\hline$c^{\prime}$ & 2 & 5 & 2 & $\mathbf{k P a}$ & & \\
\hline$\phi^{\prime}$ & 40 & 25 & 30 & o & & \\
\hline $\mathbf{C}_{\mathrm{c}}$ & - & 0.250 & 0.500 & & & \\
\hline $\mathrm{C}_{\mathrm{r}}$ & - & 0.070 & 0.080 & & & \\
\hline $\mathbf{E}_{50}{ }^{\text {ref }}$ & 50000 & - & - & kPa & & \\
\hline $\mathbf{E}_{\text {oed }}^{\text {ref }}$ & 50000 & - & - & $\mathbf{k P a}$ & & \\
\hline $\mathbf{E}_{\text {ur }}^{\text {ref }}$ & 150000 & - & - & $\mathbf{k P a}$ & & \\
\hline OCR & 2 & 2.5 & 1 & & & \\
\hline \multicolumn{7}{|c|}{ SECTOR 1B } \\
\hline & BALLAST & ALLUVIUM & KUSDILI CLAY & WEATHERED MARL & LIMESTONE & \\
\hline & $+2.50 \sim 0.00$ & $0.00 \sim-5.00$ & $-4.00 \sim-30.00$ & $-30.00 \sim-35.00$ & $>-35.00$ & \\
\hline Model & $\begin{array}{l}\text { Hardening } \\
\text { Soil }\end{array}$ & $\begin{array}{l}\text { Softening } \\
\text { Soil }\end{array}$ & Softening Soil & Hardening Soil & Hardening Soil & Unit \\
\hline$\rho_{\mathbf{n}}$ & 22 & 18 & 17 & 19 & 22 & $\mathrm{kN} / \mathrm{m}^{3}$ \\
\hline$\rho_{d}$ & 23 & 19 & 18 & 20 & 23 & $\mathrm{kN} / \mathrm{m}^{3}$ \\
\hline$c^{\prime}$ & 2 & 5 & 2 & 25 & 150 & $\mathrm{kPa}$ \\
\hline$\phi^{\prime}$ & 40 & 25 & 30 & 25 & 25 & o \\
\hline $\mathbf{C}_{\mathrm{c}}$ & & 0.250 & 0.450 & & & \\
\hline $\mathrm{C}_{\mathbf{r}}$ & & 0.070 & 0.080 & & & \\
\hline $\mathbf{E}_{50}{ }^{\text {ref }}$ & 50000 & & & 30000 & 75000 & $\mathrm{kPa}$ \\
\hline $\mathbf{E}_{\text {oed }}^{\text {ref }}$ & 50000 & & & 30000 & 75000 & $\mathrm{kPa}$ \\
\hline $\mathbf{E}_{\text {ur }}{ }^{\text {ref }}$ & 150000 & & & 90000 & 225000 & $\mathrm{kPa}$ \\
\hline OCR & 2 & 2.5 & 1 & 4 & 8.0 & \\
\hline \multicolumn{7}{|c|}{ SECTOR 5B } \\
\hline & BALLAST & ALLUVIUM & KUSDILI CLAY & WEATHERED MARL & $\begin{array}{l}\text { MARL/ } \\
\text { LIMESTONE }\end{array}$ & \\
\hline & $+2.00 \sim 0.00$ & $0.00 \sim-4.00$ & $-4.00 \sim-26.00$ & $-26.00 \sim-30.00$ & $>-30.00$ & \\
\hline Model & $\begin{array}{l}\text { Hardening } \\
\text { Soil }\end{array}$ & Soft Soil & Soft Soil & Hardening Soil & Hardening Soil & Unit \\
\hline$\rho_{\mathrm{n}}$ & 22 & 18 & 17 & 19 & 22 & $\mathrm{kN} / \mathrm{m}^{3}$ \\
\hline$\rho_{\mathrm{d}}$ & 23 & 19 & 18 & 20 & 23 & $\mathrm{kN} / \mathrm{m}^{3}$ \\
\hline$c^{\prime}$ & 2 & 5 & 2 & 25 & 150 & $\mathrm{kPa}$ \\
\hline$\phi^{\prime}$ & 40 & 25 & 30 & 25 & 25 & o \\
\hline $\mathbf{C}_{\mathrm{c}}$ & & 0.250 & 0.500 & & & \\
\hline $\mathbf{C}_{\mathbf{r}}$ & & 0.070 & 0.080 & & & \\
\hline $\mathbf{E}_{50}{ }^{\text {ref }}$ & 50000 & & & 30000 & 75000 & $\mathrm{kPa}$ \\
\hline $\mathbf{E}_{\text {oed }}{ }^{\text {ref }}$ & 50000 & & & 30000 & 75000 & $\mathrm{kPa}$ \\
\hline $\mathbf{E}_{\text {ur }}{ }^{\text {ref }}$ & 150000 & & & 90000 & 225000 & $\mathrm{kPa}$ \\
\hline OCR & 2 & 2.5 & 1 & 4 & 8.0 & \\
\hline
\end{tabular}


Table 5 - Vertical permeability coefficients employed in the geotechnical models

\begin{tabular}{|c|c|c|}
\hline \multirow{2}{*}{ SECTOR } & \multicolumn{2}{|c|}{$k_{v}(\mathrm{~m} /$ day $)$} \\
\cline { 2 - 3 } & ALLUVIUM & KUSDILI CLAY \\
\hline 1A & $2.0 \times 10^{-6}$ & $1.0 \times 10^{-6}$ \\
\hline 1B & $2.0 \times 10^{-6}$ & $3.0 \times 10^{-6}$ \\
\hline 5B & $2.0 \times 10^{-6}$ & $5.0 \times 10^{-6}$ \\
\hline
\end{tabular}

Final settlements obtained from the FEM analysis have been found to be close to the Asaoka solution whereas 3DCONS computations gave values noticeably higher than both the FEM and Asaoka solutions. Comparison of in-situ measurements and Asaoka solution with the computed final settlements from 3DCONS and FEM models are summarized in Table 6 . The two analysis methods were compared by using percent error of the results with the Asaoka solution taken as reference. Negative percent error represents the case where calculated value is less than the reference settlement.

Table 6 - Comparison of results from 3DCONS, FEM and Asaoka

\begin{tabular}{|l|c|c|c|}
\hline SECTOR & 1A & 1B & 5B \\
\hline Final measurement $(\mathrm{mm})$ & 793 & 627 & 597 \\
\hline Time $($ days) & 1906 & 1201 & 1271 \\
\hline Estimated $s_{f}$ with Asaoka $(\mathrm{mm})$ & 873 & 714 & 612 \\
\hline Estimated time to reach the $s_{f}, t$ (Days) & 8376 & 3406 & 2396 \\
\hline Computed $s_{f}$ from FEM corresponding to $t(\mathrm{~mm})$ & 864 & 706 & 628 \\
\hline Computed $s_{f}$ from 3 DCONS corresponding to $t(\mathrm{~mm})$ & 919 & 797 & 763 \\
\hline Percent error for FEM results & $-1.0 \%$ & $-1.1 \%$ & $2.6 \%$ \\
\hline Percent error for 3DCONS results & $5.3 \%$ & $11.6 \%$ & $24.7 \%$ \\
\hline
\end{tabular}

The error in the FEM analysis remained below 5\%. However, the results from 3DCONS models deviated by $5-20 \%$ from the Asaoka solution. Thus, further analyses were carried out by FEM because the final settlements computed by FEM gave more consistent values than 3DCONS with respect to the site measurements.

\subsection{Effect of Horizontal-Vertical Permeability Ratio in Consolidation}

It is known that for a clay treated with PVD, the process is most efficient if the horizontal to vertical permeability coefficient $k_{h} / k_{v}$ is higher than unity. Accordingly, $U$ - $t$ curves were generated for different $k_{h} / k_{v}$ values to estimate the in-situ ratio by FEM. The $U-t$ curves derived from numerical analyses were then compared to the curves obtained from in situ 
measurements to reach the current $k_{h} / k_{v}$ ratios. Finally, a comparison of the FEM results with the Asaoka results was carried out.

The percent consolidation value in the derived $U$ - $t$ curves were calculated by taking the ratio of the settlement value $s$ to the final settlement $s_{f}$ obtained in the Asaoka solution.

The $U-t$ curves derived from the FEM model and the insitu measurements were plotted in the same diagram, and a horizontal line is drawn from $90 \%$ consolidation until it intersects the $U$ - $t$ curves. The $k_{h} / k_{v}$ value intersecting the field measurement curve was adopted as the actual ratio.

The results arrived at by using this approach is given in Figure 9 for Sector 1A. It was found that the horizontal from $U=\% 90$ intersected the field measurement line at $k_{h} / k_{v}=1$ and this was accepted to be the actual value in situ.

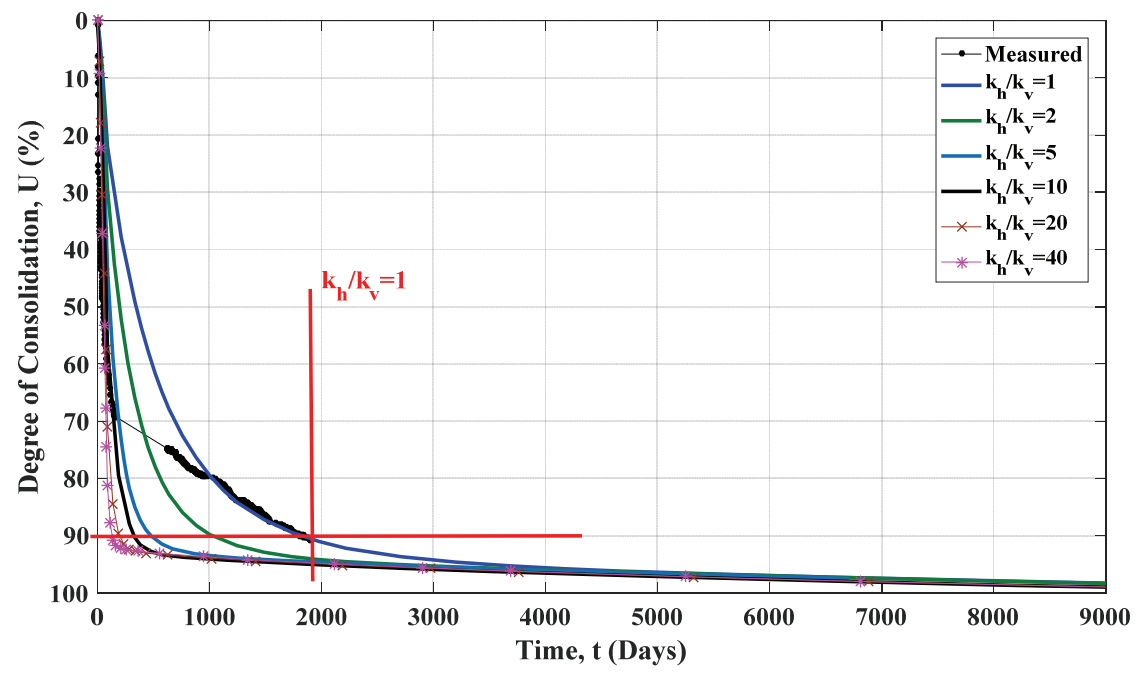

Figure 9 - Determination of $k_{h} / k_{v}$ for Sector $1 A$

Table 7 summarises the $k_{h} / k_{v}$ values calculated for all sectors, using the $c_{h}$ value inferred from Asaoka and the method illustrated in Figure 9.

Table 7 - Comparison of $k_{h} / k_{v}$ from FEM with Asaoka solution

\begin{tabular}{|c|c|c|c|c|c|}
\hline SECTOR & $c_{v}\left(\mathbf{m}^{2} / \mathbf{d a y}\right)$ & $\begin{array}{c}\boldsymbol{k}_{\boldsymbol{v}} \\
(\mathbf{m} / \mathbf{d a y})\end{array}$ & $\begin{array}{c}\text { Asaoka } \\
\boldsymbol{c h}_{\boldsymbol{h}}\left(\mathbf{m}^{2} / \mathbf{d a y}\right)\end{array}$ & $\begin{array}{c}\text { Asaoka } \\
\boldsymbol{k}_{h} / \boldsymbol{k}_{\boldsymbol{v}}\end{array}$ & $\begin{array}{c}\text { FEM } \\
\boldsymbol{k}_{\boldsymbol{h}} / \boldsymbol{k}_{\boldsymbol{v}}\end{array}$ \\
\hline $\mathbf{1 A}$ & $3.5 \times 10^{-4}$ & $1.0 \times 10^{-6}$ & $3.5 \times 10^{-4}$ & 1 & 1 \\
\hline $\mathbf{1 B}$ & $1.0 \times 10^{-3}$ & $3.0 \times 10^{-6}$ & $5.1 \times 10^{-3}$ & 5 & 3 \\
\hline $\mathbf{5 B}$ & $2.0 \times 10^{-3}$ & $5.0 \times 10^{-6}$ & $7.2 \times 10^{-4}$ & 4 & 5 \\
\hline
\end{tabular}


The results show that the Asaoka and FEM solutions indicated almost identical permeability ratios. The $\Delta$-t curves from field monitoring, Asaoka and FEM are depicted in Figure 10.

Sector 1A constitutes a special case in this study. $\Delta$-t curves from Asaoka and FEM for this sector indicated that the time required to reach the final settlement of $s_{f}=873 \mathrm{~mm}$ is more than 8000 days. This is a clear indication of the influence of the $k_{h} / k_{v}=1$ ratio slowing down the process despite the presence of PVD.

The time required to reach the final settlement of $s_{f}=714 \mathrm{~mm}$ at Sector $1 \mathrm{~B}$ was calculated to be around 3000 days. Similarly, time required to reach the final settlement of $s_{f}=612 \mathrm{~mm}$ at Sector 5B was predicted to be within 2000 days, with almost identical Asaoka and FEM results. It is confirmed from foregoing findings that $k_{h} / k_{v}$ is the controlling factor in the process of preloading with PVD.

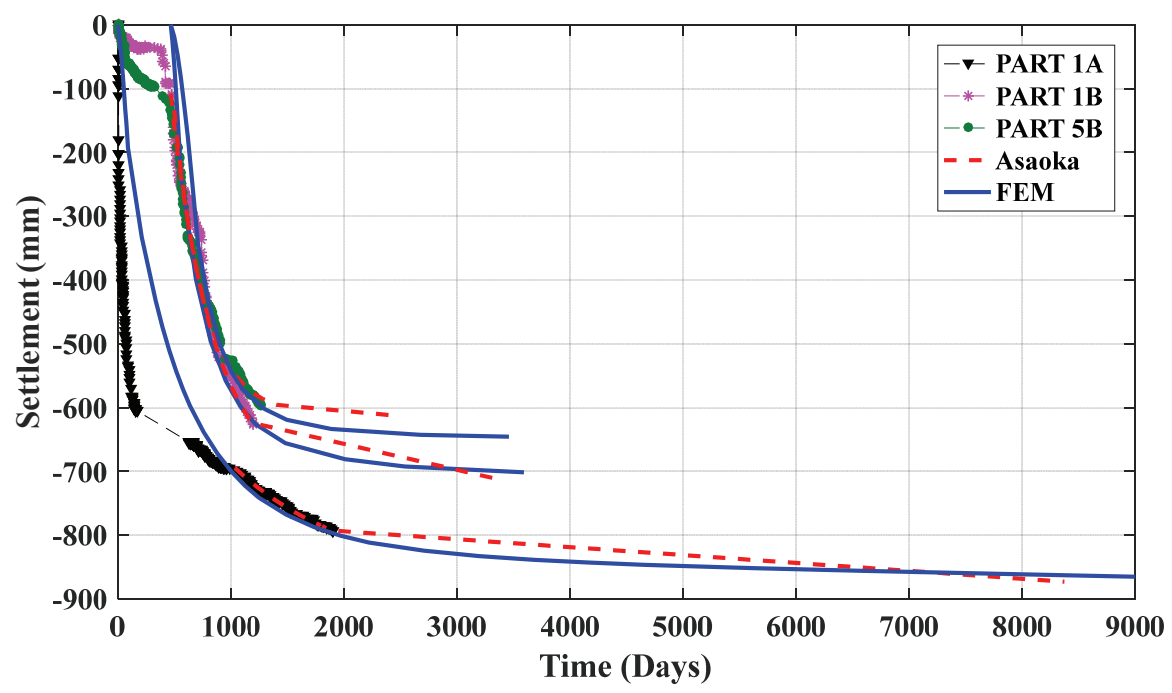

Figure 10 - Measured and FEM settlement-time curves

\subsection{The Effect of Drain Spacing}

This part of the study was carried out by keeping the $k_{h} / k_{v}$ ratios and the lengths of the PVD constant, while the effect of varying the drain spacing $s_{\text {drain }}$ on consolidation rates. Field measurements and estimation of $\Delta$-t curves by Asaoka were compared to the FEM solutions for different drain spacings, $s_{\text {drain }}$ being increased from $0.5 \mathrm{~m}$ to $3.0 \mathrm{~m}$ by steps of $0.5 \mathrm{~m}$. Figure 11 illustrates the effect of changing drain spacing on the $\Delta$-t curves. Settlement corresponding to $95 \%$ of the total was calculated and the $\Delta$-t curves were intersected with the horizontal drawn from this ordinate $\left(U_{95}\right)$. The position of $t_{95}$ on the curve determines the interval of the required drain spacing. It can be seen from the curve that for Sector A the drain spacing to reach $95 \%$ of the total settlement in 4856 days must be 1 to $1.5 \mathrm{~m}$.

The $t_{95}$ values and the corresponding $s_{\text {drain }}$ were calculated for sectors $1 \mathrm{~A}, 1 \mathrm{~B}, 5 \mathrm{~B}$ in the same fashion and are compared to the values provided by the Asaoka solution in Table 8. 


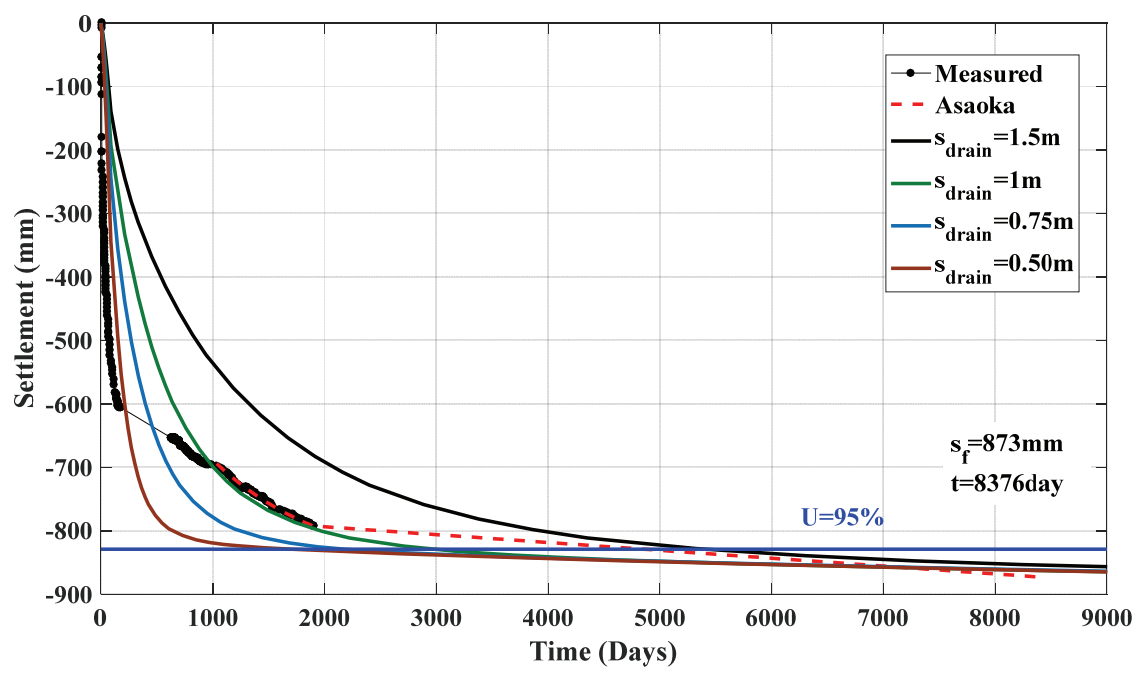

Figure 11 - The effect of variable drain spacing $\left(s_{\text {drain }}\right)$ on settlement

Table 8 - $t_{95}$ values for different $s_{\text {drain }}$ values and Asaoka solution

\begin{tabular}{|l|c|c|c|}
\hline & SECTOR 1A & SECTOR 1B & SECTOR 5B \\
\hline $\begin{array}{l}\text { Last in-situ measurement } \\
\text { recorded (mm) }\end{array}$ & 793 & 627 & 597 \\
\hline Time (Days) & 1906 & 1201 & 1271 \\
\hline & \multicolumn{3}{|c|}{ t95 (Days) } \\
\hline Asaoka Solution & 4856 & 2519 & 1236 \\
\hline$s_{\text {drain }}=0.5 \mathrm{~m}$ & 1775 & - & - \\
\hline$s_{\text {drain }}=0.75 \mathrm{~m}$ & 2261 & - & - \\
\hline$s_{\text {drain }}=1 \mathrm{~m}$ & 3012 & 933 & 799 \\
\hline$s_{\text {drain }}=1.5 \mathrm{~m}$ & 5414 & 1305 & - \\
\hline$s_{\text {drain }}=2 \mathrm{~m}$ & - & 1683 & 1045 \\
\hline$s_{\text {drain }}=2.5 \mathrm{~m}$ & - & 2268 & 1221 \\
\hline$s_{\text {drain }}=3 \mathrm{~m}$ & - & 2699 & 1423 \\
\hline
\end{tabular}

\subsection{The Effect of Drain Length on Consolidation Settlement}

The length of PVD on the rate of consolidation carries equal weight to spacing in the process of preconsolidation, especially if they do not reach a permeable layer at the bottom. Accordingly, the influence of drain length on consolidation was evaluated by increasing $L_{d r a i n}$ 
from 15 to $30 \mathrm{~m}$ using FEM. $\Delta$-t curves for this case were developed keeping $s_{d r a i n}$ and $k_{h} / k_{v}$ constant.

The $t_{95}$ projected by Asaoka was compared to those obtained by the FEM. $s_{\text {drain }}$ values were calculated using the procedure described above. The result of the analysis for Sector 1A is given in Figure 12, indicating the band $15<L_{\text {drain }}<20 \mathrm{~m}$ to reach $t_{95}$ in 2519 days. The interval changed to $20<L_{\text {drain }}<25 \mathrm{~m}$ at Sector $1 \mathrm{~B}$ and Sector $5 \mathrm{~B}$.

The findings of this section suggest that drain lengths used were insufficient to reach the EOP within the specified periods. The influence of changing drain lengths on EOP times are summarized in Table 9.

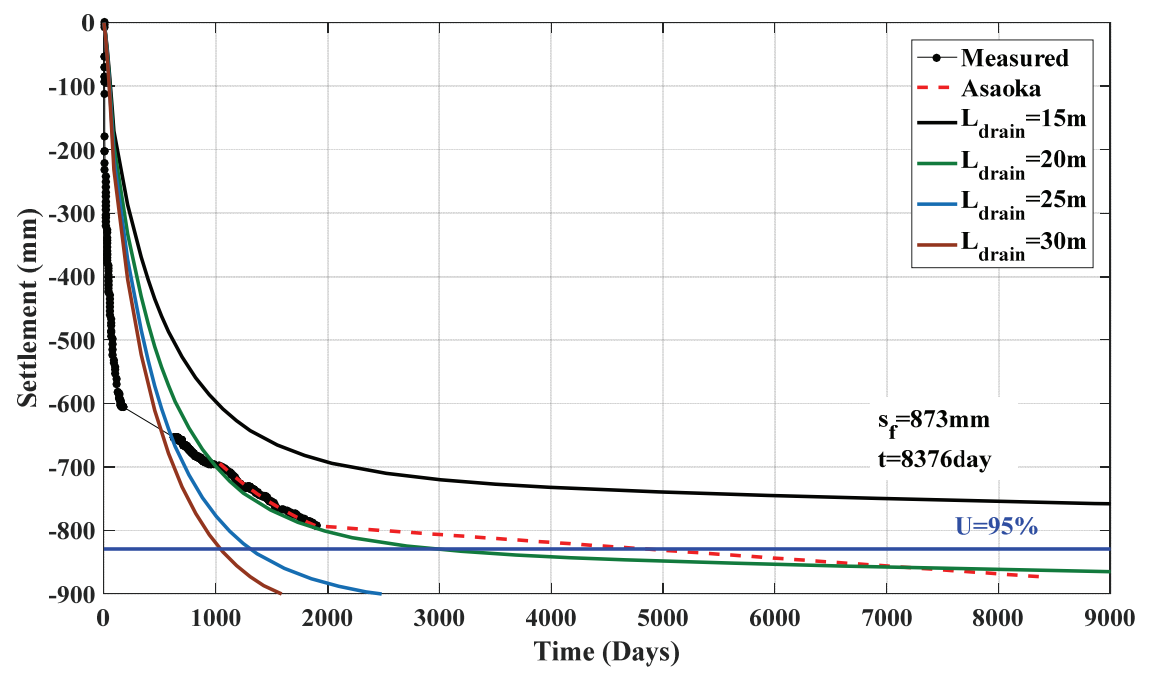

Figure 12 - The influence of $L_{\text {drain }}$ variation

Table 9 - $t_{95}$ values for varying $L_{d r a i n}$ and the Asaoka solution

\begin{tabular}{|l|c|c|c|}
\hline & SECTOR 1A & SECTOR 1B & SECTOR 5B \\
\hline Last Measurement (mm) & 793 & 627 & 597 \\
\hline Elapsed Time (Days) & 1906 & 1201 & 1271 \\
\hline & \multicolumn{3}{|c|}{$\boldsymbol{t}_{95}$ (Days) } \\
\hline Asaoka Solution & 4856 & 2519 & 1236 \\
\hline$L_{\text {drain }}=15 \mathrm{~m}$ & $>9000$ & - & $>2500$ \\
\hline$L_{\text {drain }}=20 \mathrm{~m}$ & 3012 & $>3500$ & 1508 \\
\hline$L_{\text {drain }}=25 \mathrm{~m}$ & 1316 & 1690 & 1055 \\
\hline$L_{\text {drain }}=30 \mathrm{~m}$ & 1047 & 1213 & 1012 \\
\hline
\end{tabular}


Calculations suggest that the EOP was significantly delayed in the case where $L_{\text {drain }}$ was shorter than $20 \mathrm{~m}$ with the result that the time to reach the foreseen $s_{f}$ would be reached beyond acceptable limits.

\section{DISCUSSION}

Numerical analyses with finite element method and three-dimensional consolidation software 3DCONS were carried out for three sectors of a PVD-improved area which exhibited delayed consolidation periods. The percent error for FEM results with Asaoka taken as reference, remained below 5\%, whereas 3DCONS models showed higher errors up to $5-20 \%$. Furhermore, $k_{h} / k_{v}$ from FEM models were found to be close or equal to the ratio obtained by Asaoka solution.

For Sector 1A, it was predicted by Asaoka procedure that the EOP duration would extend beyond 8000 days to reach the total settlement of $s_{f}=873 \mathrm{~mm}$. While $714 \mathrm{~mm}$ settlement predicted by Asaoka solution would be completed beyond 3000 days at Sector 1B. $k_{h} / k_{v}$ values were calculated as 1 and 3 and the estimated final settlements and periods by the analyses gave higher values than the site measurements. Consequently, it was deduced that radial drainage which is the main purpose of PVD improvement was not been achieved extending the consolidation process.

For Sector 5B, where the permeability ratio was calculated as 5, PVD application was found to be more efficient than the other two problematic sectors. The preload for this sector was started after 467 days and the last measured settlement was $597 \mathrm{~mm}$. Compared to the final settlement of $612 \mathrm{~mm}$ predicted by Asaoka, $95 \%$ of the final settlement had already been reached in the field. However, the EOP in Sector 5B was extended beyond 1200 days possibly due to the impact of surcharge placed on the adjacent sector Sector 1B, as expected.

Conflicting results were reached in studying the effect of drain spacing and length. For all the sectors, numerical analyses were carried out along with the insitu measurements to determine the required drain spacing and length. The analyses disclosed that implemented PVD design as described in Table 1 was unsatisfactory. Drain spacings were found to be larger than required by the analyses. Similarly, it has been demonstrated that PVD should have penetrated to sufficient depth in order that the actual EOPs would match the estimated limits.

A question may be posed here as to whether the low draining capacity detected may have been due to PVD creasing. However, because the settlements in the order of $70 \mathrm{cms}$ are relatively low (i.e. smaller than $15 \%$ of the original clay depth) to activate significant creasing in lengths of $20 \mathrm{~m}$ or more, the probability of creasing was considered to be negligible [20, 21].

The reason for low permability ratio $k_{h} / k_{v}$ especially in Sector $1 \mathrm{~A}$, is believed to be emanating either from inherent property of the marine/lacustrine clays studied, or due to possible smear effect which might have arisen during installation [22, 23]. 


\section{CONCLUSIONS}

A consolidation settlement analysis has been performed for the sectors a PVD-improved project area in Istanbul which exhibited prolonged consolidation beyond the expected period. The effect of changing the PVD parameters $\left(k_{h}, s_{\text {drain }}\right.$ and $\left.L_{\text {drain }}\right)$ on consolidation has been investigated to provide answers to this surprising behavior.

1. FEM models gave results in agreement with the site measurements. Finite element method re-calculates the porewater pressures for stress level at every stage of the analysis; hence, the soil behavior can be reflected realistically.

2. It was confirmed through the analyses that the consolidation process was extended beyond the expected durations. The main reason is believed to be the horizontal and vertical permeability ratios of the soils being quite close at this site. It is not clear whether this is due to the unique property of the clays at the site, or the effect of smearing. According to the analysis results, PVD implementation was not efficient in clays having $k_{h} / k_{v}$ of approximately unity.

3. The main conclusion of this study was to discover the necessity for optimizing the variables in similar projects. The efficacy of the works can be significantly enhanced if simultaneous evaluation of the parameters $s_{\text {drain }}$ and $L_{\text {drain }}$ and the permeability ratio $k_{h} / k_{v}$ is carried out prior to field work. Otherwise, "accidents" may emerge as found out in this project.

In addition to the standard analyses, the effect of secondary consolidation must also be investigated which may emerge as a critical issue in Recent clay deposits. One of the reasons of extended settlements can be attributed to secondary compression or creep effect, although no evidence of secondary consolidation was detected in the laboratory test results carried out for this project.

\section{References}

[1] Terzaghi K (1925) Erdbaumechanik. Franz Deuticke, Leipzig and Vienna.

[2] Terzaghi K (1943) Theoretical Soil Mechanics. Wiley, New York.

[3] Biot MA (1941) General Theory of Three-Dimensional Consolidation. Journal of Applied Physics 12: 155-164.

[4] Carillo N (1942) Simple two- and three-dimensional cases in the theory of consolidation of soils. Journal of Mathematics and Physics 21: 1-5.

[5] Rendulic L (1935) Der hydrodynamische Spannungsausgleich in zentral entwasserten Tonzylindern. Wasserwirtschaft und Technik 2: 250-253, 269-273.

[6] Barron RA (1948) Consolidation of fine-grained soils by drain wells. Transactions of ASCE 113: 718-754.

[7] Richart FE (1959) Review of the theories for sand drains. Transactions of ASCE 124: 709-736.

[8] Kjellman W (1948) Consolidation of fine-grained soils by drain wells. Transactions of ASCE 113, Contribution to the discussion. 
[9] Budhu B (2010) Soil Mechanics and Foundations.3 ${ }^{\text {rd }}$ Ed. John Wiley and Sons, New York.

[10] Indraratna B, Rujikiatkamjorn C, Balasubramaniam AS, McIntosh G (2012) Soft ground improvement via vertical drains and vacuum assisted preloading. Geotextiles and Geomembranes 30:16-23

[11] Indraratna B, Zhong R, Fox PJ, Rujikiatkamjorn C (2017) Large-strain vacuum-assisted consolidation with non-Darcian radial flow incorporating varying permeability and compressibility. Journal of Geotechnical and Geoenvironmental Engineering 143(1): 04016088

[12] Hu YY, Zhou WH, Cai YQ (2014) Large-strain elastic viscoplastic consolidation analysis of very soft clay layers with vertical drains under preloading. Canadian Geotechnical Journal 51(2): 125-126

[13] Bergado DT, Balasubramaniam AS, Fannin RJ, Holtz RD (2002) Prefabricated vertical drains (PVDs) in soft Bangkok clay: a case study of the new Bangkok International Airport project. Canadian Geotechnical Journal 39: 304-315

[14] Chu J, Yan SW, Yang H (2000) Soil improvement by the vacuum preloading method for an oil storage station. Géotechnique 2000 50(6): 625-632

[15] Zhuang Y, Cui XY (2016) Evaluation of Vacuum Preloading with Vertical Drains as a Soft Soil Improvement Measure. Soil Mechanics and Foundation Engineering 53: 210217.

[16] ASTM D2487 (2017) Standard Practice for Classification of Soils for Engineering Purposes (Unified Soil Classification System), ASTM International, West Conshohocken, PA, www.astm.org.

[17] Hansbo S, Jamiolkowski M, Kok L (1981) Consolidation by vertical drains. Géotechnique 31: 45-66.

[18] Asaoka A (1978) Observational Procedure of Settlement Prediction. Soils and Foundations 18: 87-101.

[19] Hausmann MR (1990) Engineering Principles of Ground Modification. McGraw-Hill, Singapore.

[20] Hansbo S (1983) How to evaluate the properties of prefabricated drains. Proc. $8^{\text {th }}$ European Conference on Soil Mechanics and Foundation Engineering, Helsinki, pp. 621-626.

[21] Miura N, Chai JC, Toyota K (1998) Investigation on some factors affecting discharge capacity of prefabricated vertical drains. Proc. $6^{\text {th }}$ International Conference on Geosynthetics, Atlanta, Georgia, pp. 845-850.

[22] Hansbo S (1987) Design aspects of vertical drains and lime column installation. Proc. $9^{\text {th }}$ Southeast Asian Geotechnical Conference, Bangkok, Thailand, pp. 8-12.

[23] Bergado DT, Asakami H, Alfaro MC, Balasubramaniam AS (1991) Smear effects of vertical drains on soft Bangkok clay. Journal of Geotechnical Engineering 117: 15091530. 
